\title{
The anomalous warming of summer 2003 in the surface layer of the Central Ligurian Sea (Western Mediterranean)
}

\author{
S. Sparnocchia ${ }^{1}$, M. E. Schiano ${ }^{2}$, P. Picco ${ }^{3}$, R. Bozzano ${ }^{4}$, and A. Cappelletti ${ }^{5}$ \\ ${ }^{1}$ CNR-ISMAR-TS, Viale R. Gessi 2, 34123 Trieste, Italy \\ ${ }^{2}$ CNR-ISMAR-SP, Forte S. Teresa, 19036 Pozzuolo di Lerici (SP), Italy \\ ${ }^{3}$ ENEA-CRAM, Forte S. Teresa, 19036 Pozzuolo di Lerici (SP), Italy \\ ${ }^{4}$ CNR-ISSIA-GE, Via dei Marini 6, 16149 Genova, Italy \\ ${ }^{5}$ ENEA-PISA, Via V. Viviani 23, 56124 Pisa, Italy
}

Received: 17 January 2005 - Revised: 16 December 2005 - Accepted: 27 January 2006 - Published: 23 March 2006

\begin{abstract}
Meteorological and sea temperature data from the ODAS Italia 1 buoy (Ligurian Sea, Western Mediterranean) are used to study the anomalous warming of summer 2003 at sea. The event was related to the record heat wave that interested much of Europe from June to September of that year. The data show that the anomalous warming was prevalently confined to within a few meters below the sea surface. On the contrary, the temperatures in the underlying layers were lower than usual. The limited vertical propagation of heat is ascribed to the high temperature difference that arose between the surface and the deeper layers due to protracted calm weather conditions. The degree of penetration of heat deduced from the observations is consistent with that computed on the basis of an energetic argument, wherein the wind constitutes the sole supply of kinetic energy, while the heating is viewed as the source of potential energy that must be "subtracted" by mixing. The results support the hypothesis that the scanty energy from the wind is mainly responsible for the development of the temperature anomaly at the sea surface.
\end{abstract}

Keywords. Oceanography: Physical (Air-sea interactions; upper ocean processes)

\section{Introduction}

The summer of 2003 in Europe was characterised by an extreme drought and a record heat wave which had enormous adverse social, economical and environmental effects, such as heat-related illnesses and deaths of elderly people, destruction of large areas of forests by fire, and impacts on water ecosystems and glaciers (WHO, 2003; De Bono et al., 2004). The event began in June 2003 and continued until mid-August, increasing the air temperature about 3 to $6^{\circ} \mathrm{C}$

Correspondence to: S. Sparnocchia

(stefania.sparnocchia@ts.ismar.cnr.it) above the seasonal average over a large portion of the european continent (Beniston, 2004; Schär et al., 2004). This extreme weather was caused by the persistency over Spain and the Central Mediterranean area of the subtropical anticyclone that prevented the inflow of rain-bearing depressions from the Atlantic Ocean over the continent. The exceptional situation lasted over 20 days during which very hot, dry air masses were conveyed to the area from the Sahara region.

Even if exceptional climatic events in Europe are not rare, as documented in old town chronicles and written historical archives (e.g. Pfister et al., 1999), the heat wave of summer 2003 was certainly an exceptional episode, at least for the last century, and was viewed by some as a consequence of global warming (Beniston, 2004; Schär et al., 2004).

The occurrence of this warming event was also detected at sea. Analysing the ECMWF forecast products, Grazzini and Viterbo (2003) evidenced a warm, positive anomaly, building up quickly in the sea surface temperature (SST) of the Central Mediterranean Basin during May 2003. The SST anomaly became very large in the first week of June and at the end of July it had expanded, covering the whole Mediterranean with the exception of the Aegean Sea. The sea surface was uniformly much warmer than indicated by the available climatologies, with temperature increases of about $2-3^{\circ} \mathrm{C}$ in the Mediterranean Sea and $4-6^{\circ} \mathrm{C}$ in the Baltic and North Seas.

Marullo and Guarracino (2003) analysed SST data acquired from 1985 to 2003 by NOAA-AVHRR sensors, and found an increase of $3-4^{\circ} \mathrm{C}$ of the mean temperature in the Mediterranean Sea during summer 2003 with respect to the past. Looking at the horizontal SST distribution, they observed a thermal anomaly as large as $4^{\circ} \mathrm{C}$ in June in the Gulf of Lions, Ligurian, Tyrrhenian, Northern Ionian and Adriatic Seas. The event still persisted in July, but it was generally weaker (the anomaly was about $3^{\circ} \mathrm{C}$ ). It then intensified again in August, especially in the Gulf of Lions and the Ligurian Sea, where the anomaly rose back to $4^{\circ} \mathrm{C}$. In

Published by Copernicus GmbH on behalf of the European Geosciences Union. 


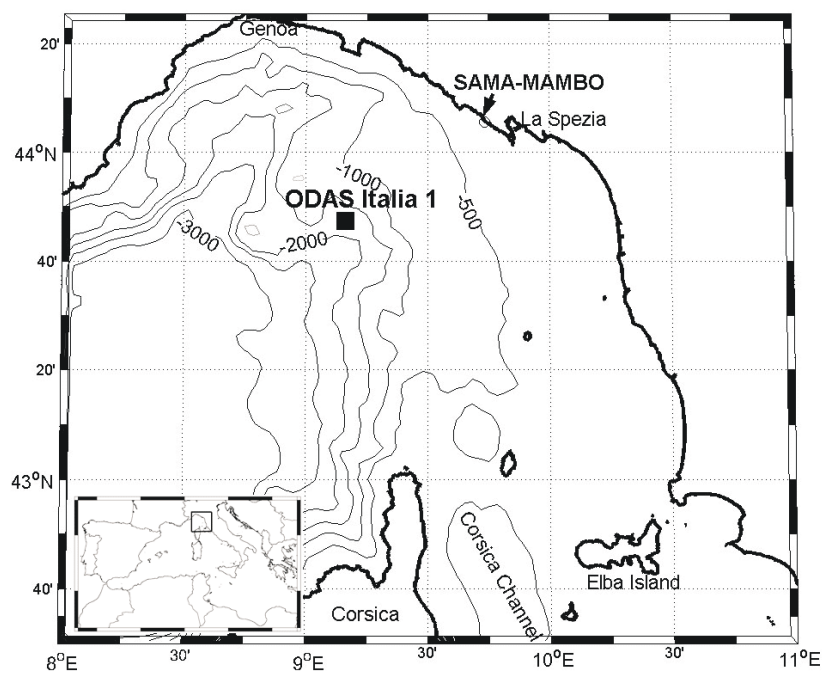

Fig. 1. Map of the Ligurian Sea showing the location of the ODAS Italia 1 buoy.

September, the event weakened perceptibly, and the recorded anomaly was below $1{ }^{\circ} \mathrm{C}$.

As they were mainly based on satellite measurements, these investigations of the anomalous warming of the sea were limited to what was occurring at the surface only. On the contrary the meteo-oceanographic observations from the moored ODAS Italia 1 buoy in the Ligurian Sea (Western Mediterranean), provided an ideal data set for studying this exceptional warming event from the surface down to a depth level of $35 \mathrm{~m}$, and aided in defining the driving conditions.

The paper is organised as follows. The general oceanographic features of the Ligurian Sea are described in Sect. 2. The observational site and the data used in this study are described in Sect. 3. In Sect. 4, the data are presented and discussed in light of an approximate energy argument. The summary and conclusions follow in Sect. 5 .

\section{Surface oceanographic conditions of the Ligurian Sea}

The Ligurian Sea (Fig. 1) is characterised by a permanent basin-wide cyclonic circulation involving both the surface and intermediate waters. More specifically, the waters flowing northwards on both sides of Corsica, the Western Corsica Current (WCC) and the Tyrrhenian Current (TC), join along the eastern periphery of the basin and form the LigurianProvençal Current (LPC), which flows westward along the coast of Provence, completing the cyclonic loop. The cyclonic circulation conditions the hydrological structure of the basin, giving rise to three main distinct zones: the coastalperipheral, the frontal and the central zones. The frontal zone divides the warmer and lighter coastal waters from the colder and denser waters of the central zone.
Data collected from the 1960s to the 1990s in the area (Le Floch, 1963; Bethoux et al., 1982; Taupier-Letage and Millot, 1986; Astraldi et al., 1990; Alberola et al., 1995) have shown that both the TC and the WCC undergo seasonal changes. Particularly, the TC is more energetic in winter than in summer when it can even reverse its direction. Data from several measurement sites northwest of Corsica indicate that the WCC intensifies in spring and weakens in late summer/autumn. However, this variation in the velocity is ascribable to a lateral displacement of the frontal zone which compresses the current against the island's continental shelf, and the associated transport seems to be constant all year round (Astraldi and Gasparini, 1992). Being the sum of the above currents, the LPC also shows a seasonal variability modulated by the TC changes. As a result of the reduction of flow through the Corsica Channel, the LPC is almost exclusively composed of water coming from the western side of Corsica in summer.

The investigated area includes the frontal zone and is influenced by the cyclonic flow. Some recent measurements, which have not yet been published, indicate the presence in this area of surface currents of $20-30 \mathrm{~cm} / \mathrm{s}$ in May and September. These velocities are not negligible but, in absence of mixing with the TC, the water constituting the flow may be regarded as homogeneous because of the steadiness of the WCC. This is also supported by satellite observations that will be shown later, which indicate a very limited horizontal temperature gradient.

\section{The ODAS Italia 1 data}

The ODAS Italia 1 buoy is a measuring platform moored in the Ligurian Sea at $43^{\circ} 47.36^{\prime} \mathrm{N}, 009^{\circ} 09.80^{\prime} \mathrm{E}$, about $73 \mathrm{~km}$ off Genoa and at a water depth of $1377 \mathrm{~m}$ (Fig. 1). It is a spar buoy about $50 \mathrm{~m}$ long and weighing 11 tons, with a small laboratory at the top, and a design (e.g. total mass, unity buoyancy at sea level, and damping disk) with negligible sensitivity to sea heave (Bertaux, 1976; Cavaleri et al., 1981). The buoy is equipped with a set of meteorological and marine sensors. The characteristics of the sensors used in this work are listed in Table 1.

Measurements are made by means of an acquisition system installed on the small laboratory on the top of the buoy. Although the acquisition system can operate with any desired sampling interval, the employed default operating mode provides a data record every hour. Acquired records are transferred in near real-time to the shore station by means of a phone link.

After a quality check, the original hourly data were averaged to obtain the daily time series analysed in this paper. Although only a few very short gaps of data occurred, essentially due to maintenance activities, the averages were computed only when at least 18 hourly data records were consecutively available, in order to avoid the gaps' influence. 
Table 1. Descriptions of the meteorological and marine sensors installed on the ODAS Italia 1 buoy which provided the data used in this paper; heights above sea level are reported as negative values.

\begin{tabular}{llll}
\hline Parameter & Sensor & Level $[\mathrm{m}]$ & Accuracy \\
\hline Sea temperature & Idromar srl - IDROWELL & $\begin{array}{l}0.5,10.5,32.0 \\
\text { (up to 31 December 2000) }\end{array}$ & $0.05^{\circ} \mathrm{C}$ \\
& & $\begin{array}{l}0.5,12.5,20.0,28.5,35.8 \\
\text { (from 1 July 2002 } \\
\text { to 30 June 2004) }\end{array}$ & $0.002^{\circ} \mathrm{C}$ \\
& & $\begin{array}{l}0.5,5.8,20.0,28.5,35.8 \\
(\text { from } 1 \mathrm{July} 2004)\end{array}$ & $0.3^{\circ} \mathrm{C}$ \\
\hline Air temperature & Rotronic ag - MP102A-T4-W4W & -12.0 & $1.5 \mathrm{hPa}$ \\
\hline Air pressure & Th. Friedrichs - 5006.0000 & -12.5 & $0.3 \mathrm{~m} / \mathrm{s}$ \\
\hline Wind speed & Th. Friedrichs -4021.0000 & -13.5 & $2.0^{\circ}$ \\
\hline Wind direction & Th. Friedrichs -4121.0000 & -13.5 & \\
\hline
\end{tabular}

\section{Results}

4.1 Evidence of the anomaly of summer 2003 in the Ligurian Sea

According to Marullo and Guarracino (2003), the anomaly of summer 2003 is clearly evident in the satellite images. Figure 2 shows the monthly averaged SST maps of the Ligurian Sea in August 2000, 2002, 2003 and 2004, available from the German Aerospace Research Center-DLR http://eoweb. dlr.de:8080/index.html. The maps reveal the strength of the anomaly and its horizontal extension. The surface temperatures of summer 2003 are markedly high when compared to the maps for the other years. Furthermore, this anomalous warming is extended over the surface of the whole basin and the SST is horizontally homogeneous $\left(28-28.5^{\circ} \mathrm{C}\right)$, both in the central and the coastal zones. During the other years, the temperature gradients across the frontal area are about $0.5^{\circ} \mathrm{C}$ in August 2000 (SST changes from $25^{\circ} \mathrm{C}$ in the central area to $25.5^{\circ} \mathrm{C}$ in the coastal zone), and $1-2^{\circ} \mathrm{C}$ in the other years (SST changes from 24 to $25.5^{\circ} \mathrm{C}$ in August 2002 and from 24 to $26^{\circ} \mathrm{C}$ in August 2004).

The vertical extent of the anomaly is shown by the sea temperature measurements recorded by the ODAS Italia 1 buoy when the data relevant to this period are confronted with those relating to the summers of 2000, 2002 and 2004 (Fig. 3): the temperature in the first $10 \mathrm{~m}$ of the water column is several degrees higher. Specifically, the temperature near the sea surface is often greater than $26^{\circ} \mathrm{C}$ in July and, in August, it systematically exceeds this value, attaining the absolute seasonal maximum of $28.6^{\circ} \mathrm{C}$ on 13 August. During the same season, in 2000, the sea surface temperature is greater than $26^{\circ} \mathrm{C}$ only around 26 August, when the seasonal
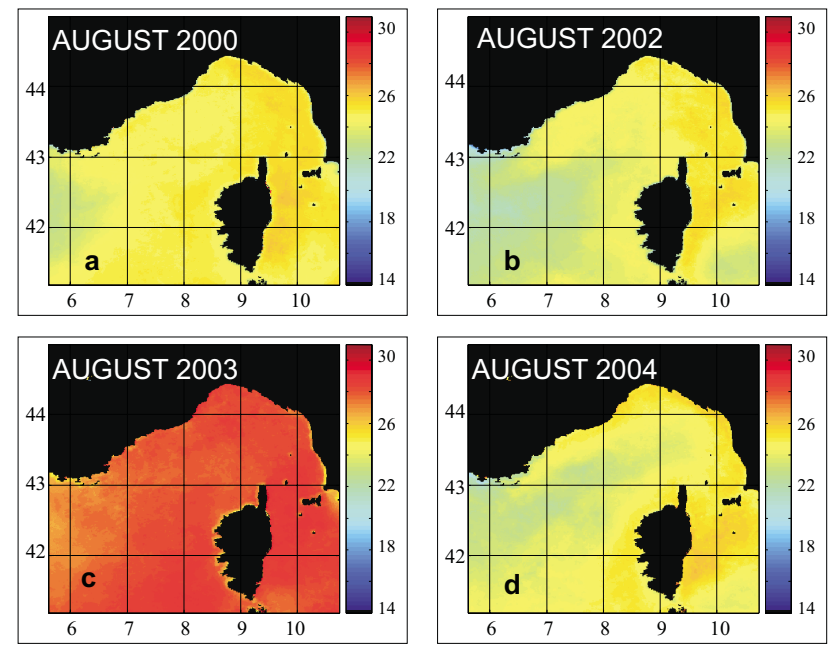

Fig. 2. Monthly averaged SST of the Ligurian Sea in (a) August 2000, (b) August 2002, (c) August 2003 and (d) August 2004.

maximum of $26.8^{\circ} \mathrm{C}$ was observed. In summer 2002 , the sea surface temperature is always less than $26^{\circ} \mathrm{C}$, reaching a maximum value of $25.5^{\circ} \mathrm{C}$ on $25 \mathrm{July}$. Even if data are not available from 25 August to 11 September 2004, we can conclude on the basis of available data that, on average, the sea surface temperature was lower than in 2003 in this case also: maximum temperatures of $25.8^{\circ} \mathrm{C}$ were detected on $12-13$ August and again on 12 September.

In summer 2003, nevertheless, only the upper layer is unexpectedly warmer, suggesting that the heat received from the atmosphere was confined to a shallow layer. In fact, below $20 \mathrm{~m}$, the water is by far colder than in 2002 and only 

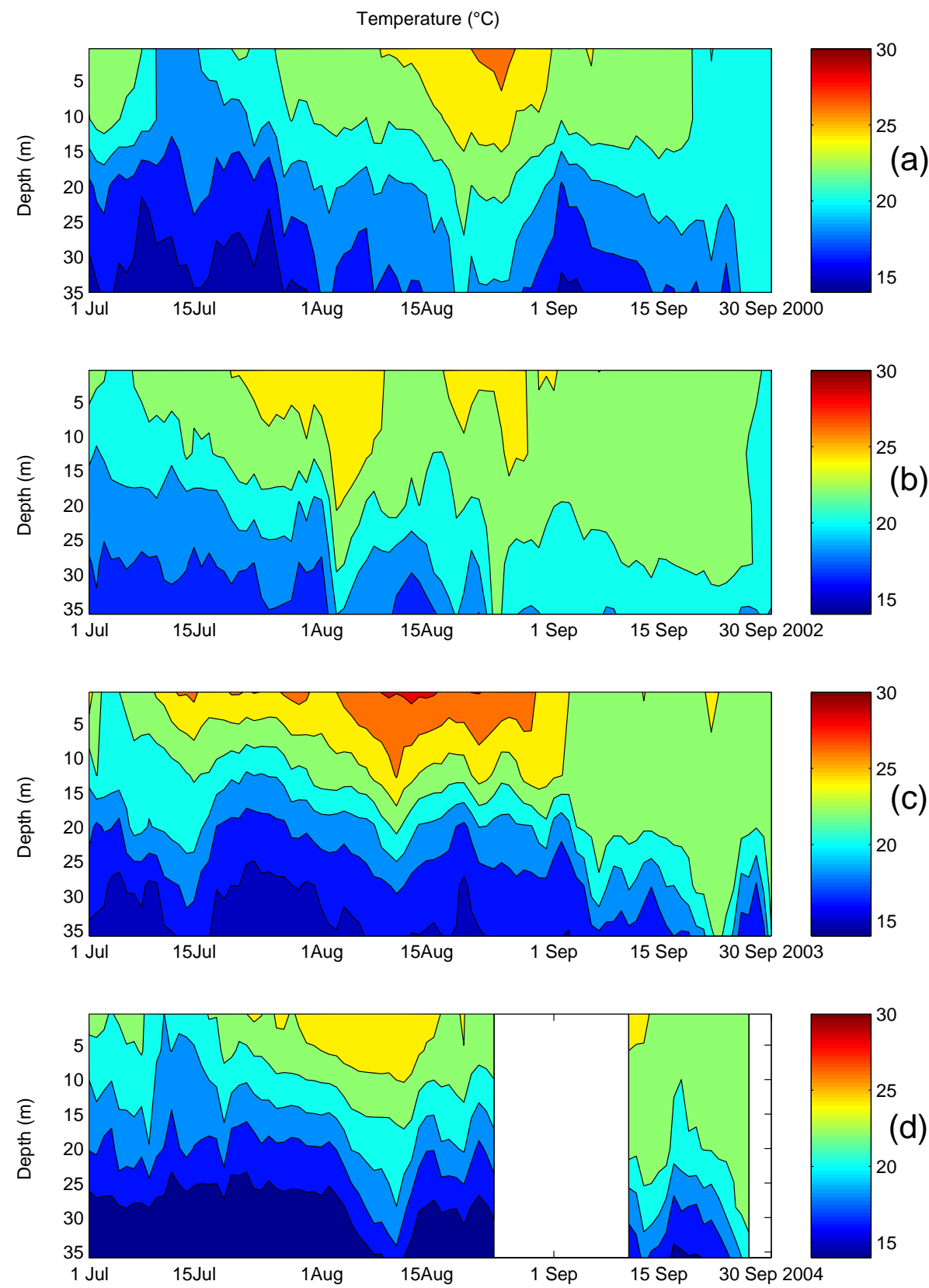

Fig. 3. Temperatures $\left({ }^{\circ} \mathrm{C}\right.$ ) from the surface to a depth level of $35 \mathrm{~m}$ in summer 2000 (a), 2002 (b), 2003 (c), and 2004 (d). Colour bars in ${ }^{\circ} \mathrm{C}$ are shown on the right and contour lines spaced $2^{\circ} \mathrm{C}$ apart are indicated in the plots.

slightly warmer than in 2004. For instance, in August 2000 and 2002, the mean temperature at a depth level of $35 \mathrm{~m}$ was $18.3^{\circ} \mathrm{C}$ and $19.0^{\circ} \mathrm{C}$, respectively, while it was $16.1^{\circ} \mathrm{C}$ in $\mathrm{Au}-$ gust 2003 and about $15^{\circ} \mathrm{C}$ in 2004 .

As a result of the limited vertical distribution of heat in summer 2003, the thermal stratification of the water column was notably higher in this period than in the other periods that were considered. In fact, the temperature gradients between the upper and the deepest levels varied from $6.2^{\circ} \mathrm{C}$ to $12.7^{\circ} \mathrm{C}$ (mean value $=10.4^{\circ} \mathrm{C}$ ) in July-August 2003, while they varied from 3.3 to $7.9^{\circ} \mathrm{C}$ (mean value $=6.4{ }^{\circ} \mathrm{C}$ ), from 1.8 to $8.3^{\circ} \mathrm{C}$ (mean value $=5.6^{\circ} \mathrm{C}$ ) and from 5.6 to $10.8^{\circ} \mathrm{C}$ (mean value $=8.7^{\circ} \mathrm{C}$ ) in July-August 2000, 2002, and 2004 (up to 24 August), respectively.

4.2 The development of the thermal anomaly in the surface layer

The thermal anomaly of summer 2003 developed at the end of May of that year, when the sea surface temperature 

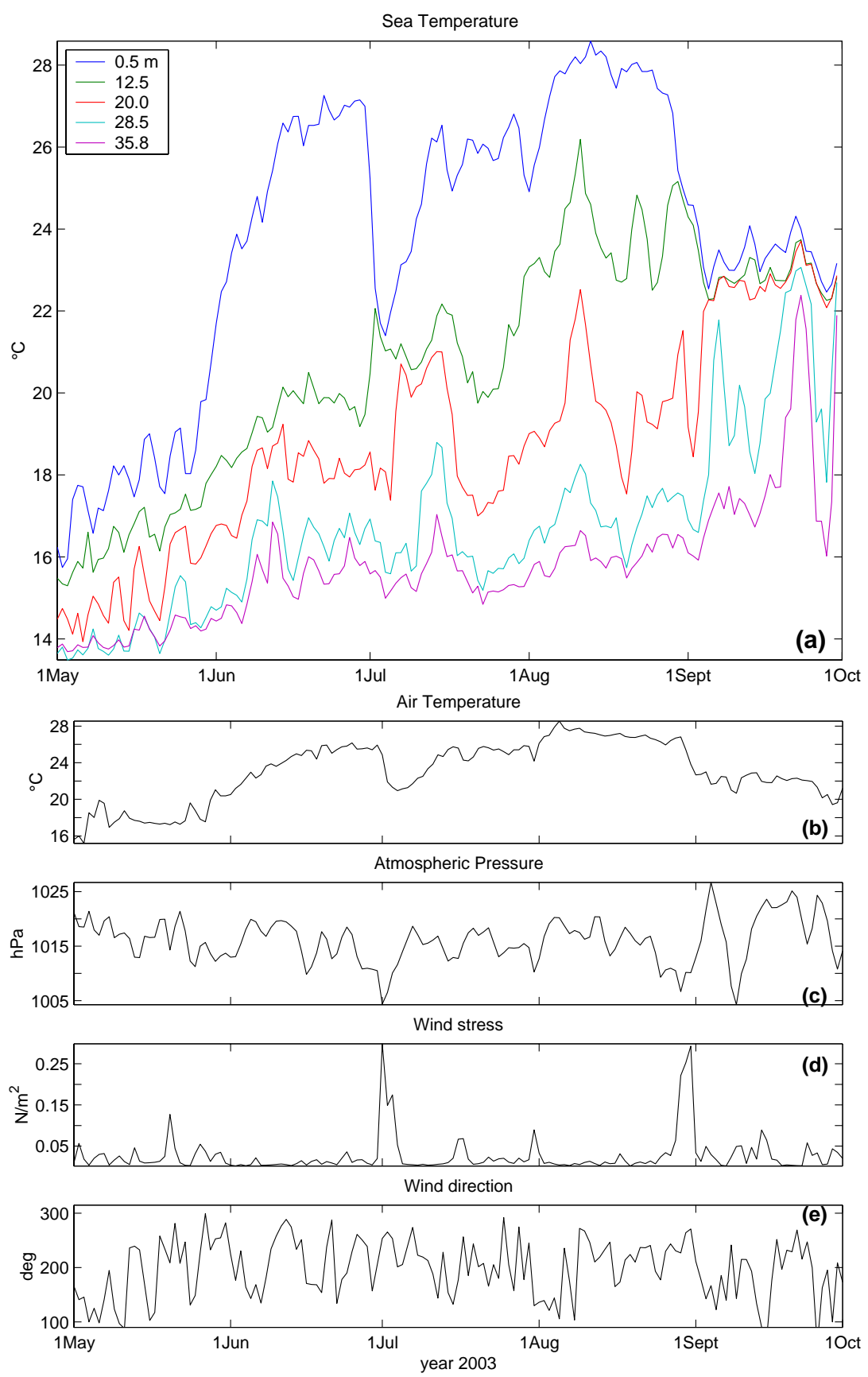

Fig. 4. Daily averaged time series from May to September 2003 of (a) the sea temperature at five depth levels, (b) the air temperature, (c) the atmospheric pressure, (d) the surface wind stress, and (e) the wind direction.

increased in three weeks from 18.5 to $26.5^{\circ} \mathrm{C}$ (Fig. 4a), closely following the evolution of the air temperature which increased from 17.7 to $25.0^{\circ} \mathrm{C}$ (Fig. $4 \mathrm{~b}$ ) in the same period. The temperature in the underlying layers also increased, but more slowly, following a gentle rising trend. As a result, a strong vertical gradient was established between the surface and the depth level of $12.5 \mathrm{~m}$ across which the tem- perature difference was as high as $8^{\circ} \mathrm{C}$. From the beginning of May to the end of June, the atmospheric pressure was high and oscillated about a decreasing trend from 1020 to $1015 \mathrm{hPa}$ (Fig. 4c). The surface wind stress - estimated from wind measurements obtained from the buoy and computed following Fairall et al. (1996) - was dominated by high-frequency gusts with amplitudes generally lower than 


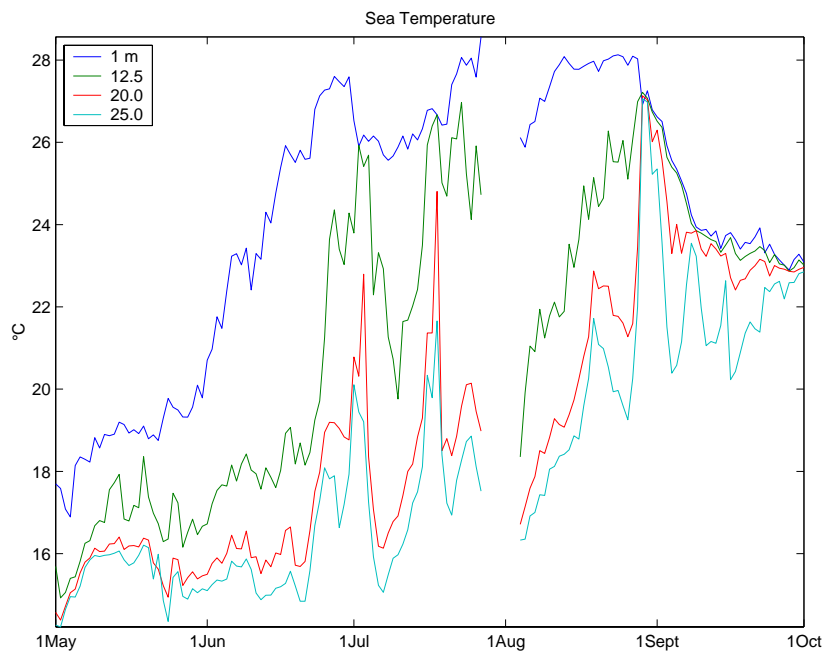

Fig. 5. Daily averaged time series from May to September 2003 of the sea temperature at four depth levels at the SAMA-MAMBO coastal site.

$0.05 \mathrm{~N} / \mathrm{m}^{2}$ (Fig. 4d). The daily averaged wind stress overcame this value only on 20 May, causing a diminution of the temperature at all the depth levels (by about $1.3^{\circ} \mathrm{C}$ near the surface and $0.4^{\circ} \mathrm{C}$ below).

A perturbation moving over the buoy site from 1 July to 3 July induced a fall of the barometric pressure from 1010 to $1004 \mathrm{hPa}$, a decrease in the air temperature from 25.5 to $21.3^{\circ} \mathrm{C}$ and an intensification of the wind field that produced surface stresses of up to $0.3 \mathrm{~N} / \mathrm{m}^{2}$. The sea surface temperature dropped from 27 to $21.4^{\circ} \mathrm{C}$, while the temperature of the underlying level (at $12.5 \mathrm{~m}$ ) rose from 19.5 to $22.0^{\circ} \mathrm{C}$. The more deeper levels were not significantly modified, except that the temperature at $20 \mathrm{~m}$ experienced a rise of roughly $2.3^{\circ} \mathrm{C}$ about five days later.

Immediately after the sudden cooling, the sea surface temperature rose again, following the air temperature, regaining about $5^{\circ} \mathrm{C}$ in eleven days and settling around $26.5^{\circ} \mathrm{C}$ on 15 July. Subsequently, the surface temperature was more or less constant until the beginning of August, apart from two small drops that were related to enhanced wind activity. In August, the sea surface temperature increased again, reaching the maximum $\left(28.6^{\circ} \mathrm{C}\right)$ of 13 August. Thereafter, it remained quite stable around $28^{\circ} \mathrm{C}$ until the end of the month, favoured by the persistence of a high pressure system, that extended over the whole Mediterranean. The temperatures at the other examined depths behaved differently. Local maxima were found around 14 July and 13 August, coincident with the steep increases of the sea surface temperature. The maxima were followed by abrupt decreases that drove the temperatures to lower values, while the temperature near the surface remained consistently high. The lack of correlation between the temperature at the sea surface and those at the deeper levels in July and August is clearly evidenced in Ta-
Table 2. Correlation coefficients of observed sea temperatures calculated by grouping data monthly. Correlations between the surface measurement and the measurements at 12.5, 20, 28.5 and $35.8 \mathrm{~m}$ are shown in columns 2 to 5 , respectively.

\begin{tabular}{lcccc}
\hline & $\mathrm{C}(0.5,12.5)$ & $\mathrm{C}(0.5,20)$ & $\mathrm{C}(0.5,28.5)$ & $\mathrm{C}(0.5,35.8)$ \\
\hline April & 0.90 & 0.83 & 0.73 & 0.67 \\
May & 0.84 & 0.62 & 0.59 & 0.67 \\
June & 0.88 & 0.67 & 0.61 & 0.62 \\
July & -0.07 & -0.06 & 0.21 & 0.19 \\
August & 0.09 & 0.05 & 0.12 & 0.01 \\
September & 0.93 & -0.43 & 0.02 & 0.19 \\
October & 1.00 & 0.99 & 0.96 & 0.86 \\
\hline
\end{tabular}

ble 2, which shows the zeroth lag correlation coefficients for the observed sea temperatures, calculated separately for each month. The sea surface temperature in July and August was totally uncorrelated with the temperatures of the underlying layers, unlike during the previous months when the correlation was around $60 \%$ and more. Correlation values for lags greater than zero (not shown here) led to the same result.

The temperature difference between the surface and the depth level immediately below reached a maximum of $6^{\circ} \mathrm{C}$ and $5^{\circ} \mathrm{C}$ in July and August, respectively, revealing once more the presence of a strong vertical gradient, although this was smaller than the one observed in June.

The period between 29 August and 1 September was characterised by strong westerly winds and a lower air temperature, and the sea surface temperature decreased to $23^{\circ} \mathrm{C}$ rapidly. The surface layer started mixing with the layers below, presaging the end of the anomaly. In October, the investigated layer had mixed completely, as the last row of Table 2 indicates.

A similar evolution of sea temperature was also observed by the meteo-oceanographic coastal buoy SAMA-MAMBO (http://192.107.66.195/[ITA]_Stations.htm) located in front of Riomaggiore $\left(44^{\circ} 05.24^{\prime} \mathrm{N}, 009^{\circ} 43.97^{\prime} \mathrm{E}\right)$, about $57 \mathrm{~km}$ northeast of the ODAS Italia 1 buoy. This buoy acquires a CTD profile every three hours from about $1 \mathrm{~m}$ to $25 \mathrm{~m}$ in depth. Figure 5 shows the daily averaged temperatures obtained from the buoy's records at depths comparable to the measurement levels of ODAS Italia 1. In spite of the obvious differences in heating and mixing processes between a coastal area and the open sea, the data from the two buoys are in good agreement with each other. In particular, the rapid heating of the surface layer and the development of the stratification in June, the long period when the temperature was prevalently higher than $26^{\circ} \mathrm{C}$ (the maximum of $28.6^{\circ} \mathrm{C}$ was recorded on 28 July), and, finally, the abrupt mixing in the period corresponding to the storm at the end of August, are well evident. Similar to what was observed at the ODAS Italia 1 site, the vertical temperature gradient was very strong near the surface, seeing that the temperature difference was as high as $7.5^{\circ} \mathrm{C}$ in the first $12 \mathrm{~m}$, both in July and August. 

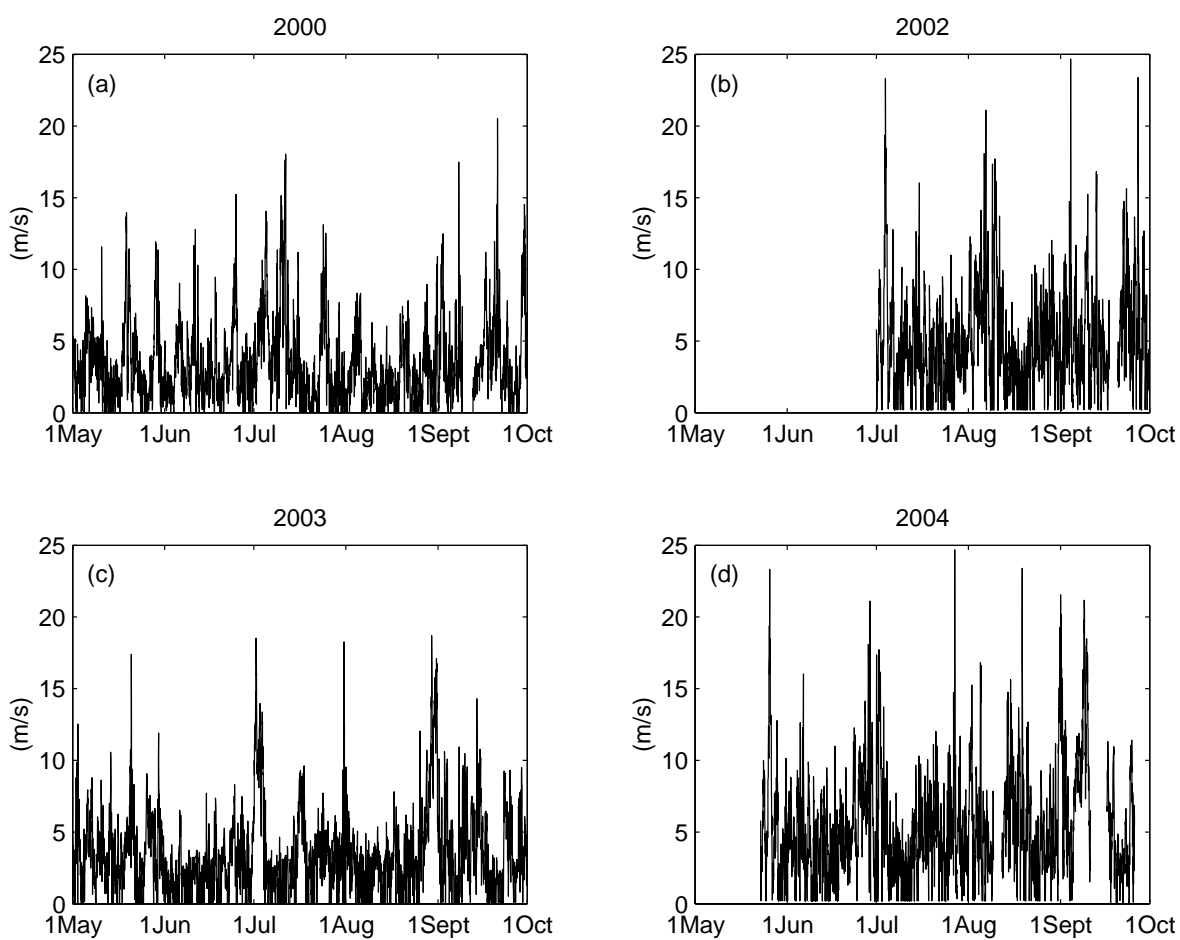

Fig. 6. Hourly wind speed $\left(\mathrm{m} \mathrm{s}^{-1}\right.$ ) from May to September 2000 (a), 2002 (b), 2003 (c), and 2004 (d).

4.3 Wind effects on the development of the thermal anomaly

The observations suggest that reduced wind activity may have been the principal cause of the temperature anomaly at the sea surface. The wind plays a role not only in the transfer of latent and sensible heat from the sea to the atmosphere, but also in the mixing of the surface layers. The analysis of the wind speed at the original time resolution (one hour) from May to September revealed that the year 2003 was characterised by long periods with low wind speeds, especially from June to August. Such long periods of persistently calm weather conditions are generally not observed during the summer months in this area, as the data collected during 2000, 2002 and 2004 confirm (Fig. 6).

Now, if the wind is not strong enough to break up the vertical stratification, it is fair to assume that the solar heat cannot propagate downward, with the result that this heat will tend to accumulate in a thin layer below the surface. To verify this assumption, a simplified energy argument was utilised that helps in evaluating the effect of the wind stress on the observed vertical stratification when all other sources of energy and any dissipation are neglected. In the ensuing scheme, the potential energy gain due to the vertical relocation of water masses through mixing is entirely balanced by the mechanical energy input of the surface wind.

This kind of 1-D approach is reasonable because the horizontal advection is negligible at the temporal-spatial scale characterising the observed thermal phenomenon. In fact, during summer, the investigated area is mainly occupied by the WCC and the horizontal thermal gradient is limited, as is evidenced by the relevant satellite images as well (see Fig. 2).

The rate at which the wind stress works on the mixing layer turbulent velocity field (e.g. the surface flux of turbulent kinetic energy, $E_{o}$ ) is usually assumed to be proportional to $\tau \cdot u_{f}$, where $\tau$ is the wind stress and $u_{f}$ is the friction velocity in the water. The latter is defined as $u_{f}=\left(\tau / \rho_{o}\right)^{1 / 2}$, so that

$E_{o} \approx m_{o} \rho_{o} u_{f}^{3}$,

where $\rho_{o}$ is a reference density value for sea water and $m_{o}$ is the proportionality factor. This factor depends on several conditions, such as atmospheric and oceanic stability, sea state, and surface roughness. Unfortunately, the exact dependencies of the factor on these variables is poorly known, and $m_{o}$ is commonly assumed to be a constant.

Under the assumption of a constant buoyancy gradient, the work per unit time needed to entrain a parcel of dense water from a depth $h$ and to lift it through the layer is (e.g. Cushman-Roisin, 1994, p. 161):

$W \approx \frac{1}{4} \rho_{o} N^{2} h^{2} \frac{d h}{d t}$, 
where $N$ is the buoyancy frequency (Brunt-Väisälä frequency):

$N=\left[-\frac{g}{\rho_{o}} \frac{\partial \rho}{\partial z}\right]^{1 / 2}$,

$g$ is the gravity and $\rho=\rho(z)$ is the water density profile.

Balancing Eqs. (1) and (2) and integrating in time, the mixing depth $D$ after a time $t$ is:

$D=\left(12 \frac{m_{o} \cdot u_{f}^{3}}{N^{2}} t\right)^{\frac{1}{3}}=\left(12 \frac{m_{o} \cdot t}{N^{2}}\right)^{\frac{1}{3}} \cdot\left(\frac{\tau}{\rho_{o}}\right)^{\frac{1}{2}}$.

Therefore, given $N^{2}, m_{o}$ and $t$, the above relationship allows for an evaluation of the action of the wind stress on the mixing depth.

Due to the lack of concurrent salinity measurements, the density variations in the computation of $N$ were assumed to be mainly driven by temperature. Thus, the squared buoyancy frequency was approximated as:

$N^{2} \approx g \alpha \frac{\partial T}{\partial z}$,

where $\alpha$ is the thermal expansion coefficient and the temperature gradient was computed as the difference between the value at the surface and that at the deepest level $(35.8 \mathrm{~m})$. An estimate of the error associated with this approximation is derived in Appendix A, using CTD profiles close to the buoy during two maintenance cruises. The results show that this approximation is reasonable. Values of $\alpha=2.710^{-4 \circ} \mathrm{C}^{-1}$, $g=9.81 \mathrm{~m} \mathrm{~s}^{-2}$ and $\rho_{o}=1028 \mathrm{~kg} \mathrm{~m}^{-3}$ were used in the calculation of $N^{2}$.

The numerical value of $m_{o}$ is uncertain and controversial (Kraus, 1988). Here we use $m_{o}=0.5$, which, at present, is the best documented estimate and was derived by Davis et al. (1981) from continuous measurements made in the vicinity of the Ocean Weather Station Papa in the northeast Pacific Ocean during the 20-day MILE experiment. A slightly higher range of $0.55 \leq m_{o} \leq 0.7$ was found later by Gaspar (1988) to fit four years of routine observations at station $\mathrm{P}$ in the Gulf of Alaska.

For a depth varying from 0 to $35 \mathrm{~m}$, the corresponding $\tau$ estimates were computed using two different values of $N^{2}$, namely, $8.3310^{-4} \mathrm{~s}^{-2}$ and $8.0510^{-4} \mathrm{~s}^{-2}$, obtained from the sea temperature data collected on 30 June and 28 August, i.e. the days preceding the two principal wind events which occurred in summer 2003 (the event of 1-3 July and that of 29-31 August).

The two different values of the buoyancy frequency used in the calculations do not significantly modify the results (Fig. 7). For instance, to mix the upper $12.5 \mathrm{~m}$ in one day, the corresponding wind stress should be at least $0.22 \mathrm{~N} / \mathrm{m}^{2}$ for both the observed stratifications, while to reach $20 \mathrm{~m}$ we need more than $0.55 \mathrm{~N} / \mathrm{m}^{2}$.
During the two events considered here, the wind blew for three days and the observed averaged wind stresses for the relative periods were, respectively, $0.21 \mathrm{~N} / \mathrm{m}^{2}$ and $0.25 \mathrm{~N} / \mathrm{m}^{2}$. In the July episode, the mixing depth computed with such a wind stress is about $17.5 \mathrm{~m}$, while during the August episode it is $19.5 \mathrm{~m}$. Temperature observations show that the upper $12.5 \mathrm{~m}$ were well mixed in both cases but the mixing did not reach the $20 \mathrm{~m}$ level in the first case and was close to $20 \mathrm{~m}$ in the second. In addition, maintaining the same stratification for two weeks and neglecting the effect of surface heating (that for longer periods would tend to increase the stratification) it was noted that a wind stress greater than $0.04 \mathrm{~N} / \mathrm{m}^{2}$ was needed to mix the upper $12.5 \mathrm{~m}$. The observations agree with these estimations, seeing that the wind stress was often under this threshold and the surface waters never mixed to this depth during the long period of persistently calm conditions recorded in summer 2003. These results tend to reinforce the idea that, given the strong stratification that had developed at the beginning of June and the low winds, the mixing depth remained above the $20 \mathrm{~m}$ depth level, effectively blocking any downward propagation of heat. Furthermore, even the release of sensible and latent heat from the sea to the air is poor, due to the low winds and the high air temperature. This obviously leads to an anomalous warming of the surface layer of the sea which will be attenuated only when the wind becomes more intense.

\section{Conclusions}

Meteorological and sea temperature data from the ODAS Italia 1 buoy (Ligurian Sea, Western Mediterranean) have been used to study the consequence of the heat wave of summer 2003 in the surface layer of the sea down to a depth of $35 \mathrm{~m}$.

The data evidenced the development of an anomaly in the sea temperature which began at the end of May and persisted throughout August, rising to a seasonal maximum $2-3^{\circ} \mathrm{C}$ higher than in previous summers.

This anomalous warming extended over the whole basin as satellite maps of monthly mean SST on the Ligurian Sea for the relevant period clearly show. However, the anomaly was confined to the surface where the temperature was up to $8^{\circ} \mathrm{C}$ higher than the one recorded at a depth of $12 \mathrm{~m}$. On the contrary, the temperatures in the underlying layers were several degrees lower than usual, even if subject to a progressive increase coherent with the seasonal trend. A similar behaviour was also detected in the vertical temperature profiles obtained from the SAMA-MAMBO coastal buoy, indicating that the phenomenon had influenced a wide area.

The formation of the temperature anomaly and its persistence at the sea surface is attributed to the presence of calm weather conditions from June to August. In fact, apart from an episode of intense wind stress (from 0.3 to $0.15 \mathrm{Nw} \mathrm{m}^{-2}$ ) at the beginning of July and two other milder 


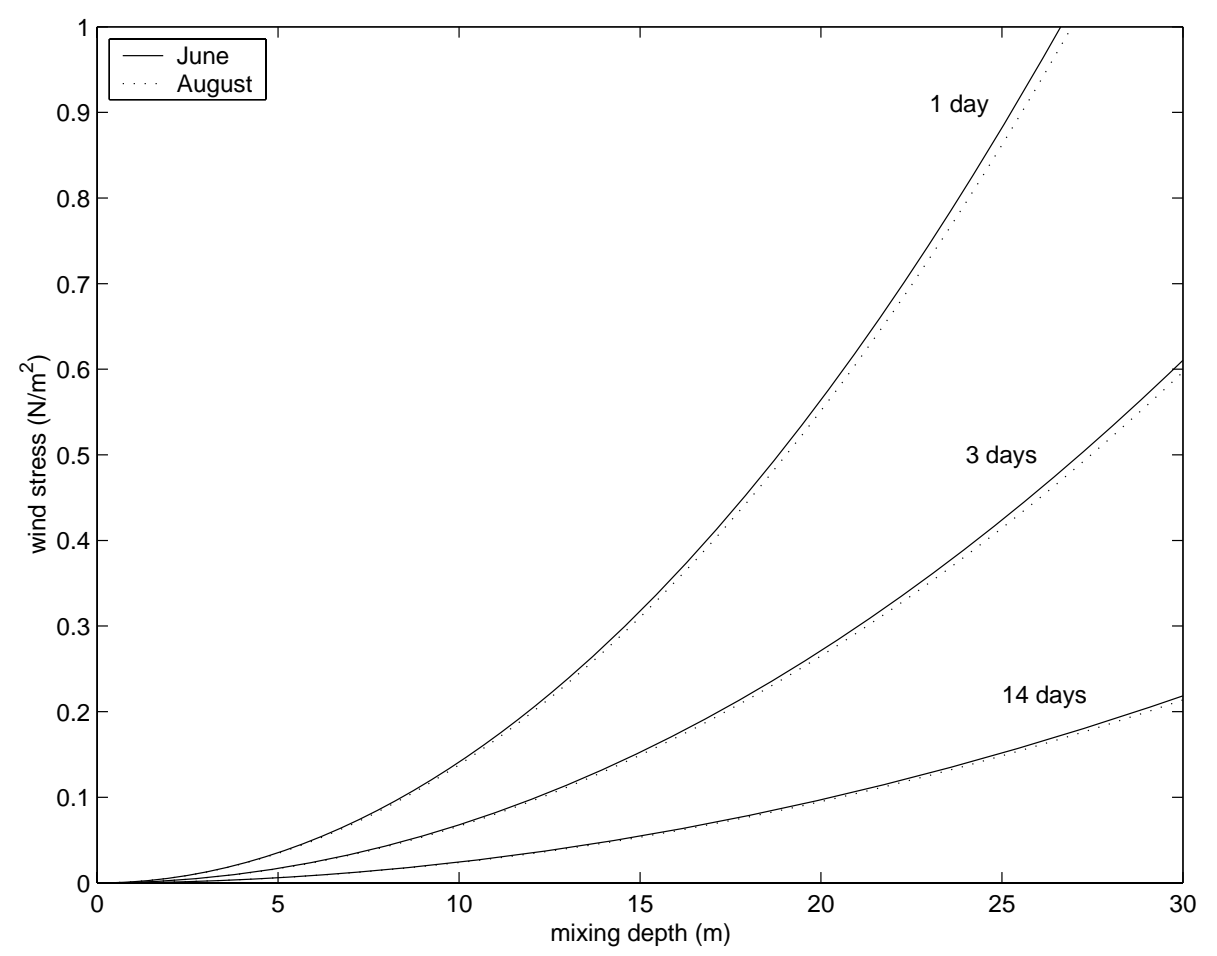

Fig. 7. Relationship between the wind stress and the mixing depth under different stratification conditions and different durations of the wind event.

episodes on 16-17 July and 31 July when the daily mean wind stresses were $0.07 \mathrm{Nw} \mathrm{m}^{-2}$ and $0.09 \mathrm{Nw} \mathrm{m}^{-2}$, respectively, the wind forcing during the examined period was well below $0.03 \mathrm{Nw} \mathrm{m}^{-2}$. Such a long period without strong winds was never observed during the other summer periods which were investigated. The weak wind limited the vertical mixing in the water column and a sharp interface developed between the surface and the layers below. Once formed, the interface acted as a barrier to the subsequent downward propagation of the heat received from the atmosphere. In other words, the heat received from the atmosphere was stored in a thin layer, where it remained until wind mixing became efficient enough to break the barrier and permitted the "trapped" heat to propagate down to deeper layers. During summer, this happened a few times, i.e. the wind eroded the interface temporarily, but the surface interface reformed once again as soon as the wind intensity decreased. The wind field intensified decisively only in September, and the anomaly disappeared.

The degree of the penetration of heat deduced from the observations is consistent with that computed on the basis of an energetic argument where the wind constituted the sole supply of kinetic energy, while the heating, seeing that it promotes vertical stratification, is viewed as the source of potential energy that must be "subtracted" by mixing. Despite the evident oversimplification and notwithstanding the several approximations which were adopted, the approach used describes the observations in a satisfactory manner and the results obtained reinforce the hypothesis that the scanty energy from the wind is mainly responsible for the development of the temperature anomaly at the sea surface.

The results of this study are also evidence of the importance of long-term meteo-oceanographic measurements in the study of air-sea interaction processes, which cannot be completely understood using satellite data only.

\section{Appendix A}

\section{Estimate of the error in the mixing depth calculation when the vertical salinity gradient is neglected}

The correct calculation of the buoyancy frequency, $N$, involves contributions by both the temperature and the salinity, as is evident from the relevant expression below:

$$
N^{2}=g\left(\alpha \frac{\partial T}{\partial z}+\alpha \Gamma\right)-g \beta \frac{\partial S}{\partial z},
$$

where $\alpha$ and $\beta$ are the thermal expansion and the salinity contraction coefficients, and $\Gamma$ is the adiabatic lapse rate. The term involving $\Gamma$ is three orders of magnitude smaller than the one involving the temperature gradient, so it can be neglected in the actual computation.

In Table A1, the two contributions made by the vertical gradients of temperature and salinity, calculated from CTD 
Table A1. The depth-averaged contributions of temperature and salinity to the vertical stratification in the 0 to $35 \mathrm{~m}$ depth range.

\begin{tabular}{lcc}
\hline & April 2003 & September 2003 \\
\hline$N_{T}^{2}=g \alpha \frac{\partial T}{\partial z}\left(10^{-4} \mathrm{~s}^{-2}\right)$ & 2.11 & 5.12 \\
$N_{S}^{2}=-g \beta \frac{\partial S}{\partial z}\left(10^{-4} \mathrm{~s}^{-2}\right)$ & 0.31 & -1.09 \\
$\frac{D-D_{T}}{D}$ & -0.05 & 0.08 \\
\hline
\end{tabular}

casts close to the buoy during two maintenance cruises in April 2003 and September 2003, are compared. The salinity contribution is positive in spring and negative in summer, and represents generally only $15-20 \%$ of the temperature contribution in size. Indicating the approximate mixed layer depth, as calculated in Sect. 4.3 by $D_{T}$, and the true mixed layer depth by $D$, the percentage error is $\frac{D-D_{T}}{D}=1-\left(\frac{N_{T}^{2}+N_{S}^{2}}{N_{T}^{2}}\right)^{1 / 3}$ and is shown in the third row of Table A1. The error associated with the estimate caused by neglecting the salinity contribution is $-5 \%$ in April and $+8 \%$ in September. So, a calculated depth of $10 \mathrm{~m}$ will correspond to $9.5 \mathrm{~m}$ in April (spring) and $10.8 \mathrm{~m}$ in September (summer). Given the declared aims of the paper, these errors are small enough to be acceptable, and approximation (5) is justified.

Acknowledgements. The authors gratefully acknowledge M. Borghini (ISMAR-CNR) for his technical support and R. Nair for useful comments. Data from the SAMA MAMBO buoy were kindly provided by A. Lisca and A. Bordone from ENEA CRAM. The authors also wish to thank the German Aerospace Research Center-DLR for the satellite data and the two anonymous reviewers for their helpful comments. This work was partially funded by the Ministero dell'Istruzione, dell'Università e della Ricerca (MIUR) within the framework of the ENEA-MIUR joint programme, "Mediterranean Environment", under contract 3.3.2.4: "Validation of geophysical parameters", and by the EU Project: "Mediterranean Forecasting System: Toward Environmental Predictions" (MFSTEP), Contract Number EVK3-CT-2002-00075.

Topical Editor N. Pinardi thanks two referees for their help in evaluating this paper.

\section{References}

Alberola, C., Millot, C., and Font, J.: On the seasonal and mesoscale variabilities of the Northern Current during the PRIMO-0 experiment in the western Mediterranean Sea, Ocean. Acta, 18(2), 163-192, 1995.

Astraldi, M. and Gasparini, G. P.: The seasonal characteristics of the circulation in the north Mediterranean basin and their relationship with the atmospheric-climatic conditions, J. Geophys. Res., 97(C6), 9531-9540, 1992.

Astraldi, M., Gasparini, G. P., Manzella, G. M. R., and Hopkins, T.: Temporal variability of currents in the eastern Ligurian Sea, J. Geophys. Res., 95(C2), 1515-1522, 1990.
Beniston, M.: The 2003 heat wave in Europe: A shape of things to come? An analysis based on Swiss climatological data and model simulations, Geophys. Res. Lett., 31, L02202, doi:10.1029/2003GL018857, 4, 2004.

Bertaux, H. O.: Buoy Enginering, John Wiley \& Sons, 1976.

Bethoux, J. P., Prieur, L., and Nyffeler, F.: The water circulation in the north-western Mediterranean Sea, its relations with wind and atmospheric pressure, in: Hydrodynamics of Semi-Enclosed Seas, edited by: Nihoul, J. C. J., Elsevier Oceanography Series, 34, 129-142, 1982.

Cavaleri, L. and Mollo-Christensen, E.: Wave response of a spar buoy with and without a damping plate, Ocean. Engin., 8, 1724, 1981.

Cushman-Roisin, B.: Introduction to Geophysical Fluid Dynamics, Prentice Hall, 320 pp, ISBN 0-13-353301-8, 1994.

Davis, R. E., DeSzoeke, R., and Niiler, P.: Variability in the upper ocean during MILE. Part II: Modeling the mixed layer response, Deep-Sea Res., 28A(12), 1453-1475, 1981.

De Bono, A., Pedruzzi, P., Giuliani, G., and Kluser, S.: Impacts of summer 2003 heat wave in Europe. Early Warning on Emerging Environmental Threats, UNEP/DEWA/ Europe/GRID-Geneva, 4 pp., 2004.

Fairall, C. W., Bradley, E. F., Rogers, D. P., Edson, J. B., and Young, G. S.: Bulk parameterization of air-sea fluxes for Tropical Ocean-Global Atmosphere Coupled-Ocean Atmosphere Response Experiment, J. Geophys. Res., 101(C2), 3747-3764, 1996.

Gaspar, P.: Modelling the seasonal cycle of the upper ocean, J. Phys. Oceanogr., 18, 161-180, 1988.

Grazzini, F. and Viterbo, P.: Record-breaking warm sea surface temperature of the Mediterranean Sea, ECMWF Newsletter, 98, 30-31, 2003.

Kraus, E. B.: Merits and defects of different approaches to mixed layer modelling, in: Small-scale turbulence and mixing in the ocean, edited by: Nihoul, J. C. J. and Jamart, B. M., Elsevier Oceanography Series, 46, 37-50, 1988.

Le Floch, J.: Sur les variations saisonnières de la circulation superficielle dans le secteur Nord-Est de la Méditerranée occidentale, Trans. Cent. Rech. Etud. Oceanogr., 5, 5-10, 1963.

Marullo, S. and Guarracino, M.: L'anomalia termica del 2003 nel Mar Mediterraneo osservata da satellite (Satellite observation of the 2003 thermal anomaly in the Mediterranean Sea) (in Italian), Energia, Ambiente e Innovazione, 6/03, 48-53, 2003.

Pfister, C., Brazdil, R., Glaser, R., Barriendos, M., Camuffo, D., Deutscii, M., Dobrovolny, P., Enzi, S., Guidoboni, E., Kotyza, O., Militser, S., Racz, L., and Rodrigo, F. S.: Documentary evidence on climate in sixteenth-century, Europe. Clim. Change, 43, 55-110, 1999.

Schär, C., Vidale, P. L., Lüthi, D., Frei, C., Häberli, C., Liniger, M. A., and Appenzeller, C.: The role of increasing temperature variability in European summer heatwaves, Nature, 427, 332336, 2004.

Taupier-Letage, I. and Millot, C.: General hydrodynamical features in the Ligurian Sea inferred from the DYOME experiment, Ocean. Acta, 9(2), 119-131, 1986.

WHO: The health impacts of 2003 summer heat-waves, Briefing note for Delegations of the fifty-third session of the WHO (World Health Organization) Regional Committee for Europe, $12 \mathrm{pp}$, 2003. 